\title{
Pyrochemical reprocessing of molten salt fast reactor fuel: focus on the reductive extraction step
}

\author{
Davide Rodrigues, \\ Gabriela Durán-Klie, \\ Sylvie Delpech
}

\begin{abstract}
The nuclear fuel reprocessing is a prerequisite for nuclear energy to be a clean and sustainable energy. In the case of the molten salt reactor containing a liquid fuel, pyrometallurgical way is an obvious way. The method for treatment of the liquid fuel is divided into two parts. In-situ injection of helium gas into the fuel leads to extract the gaseous fission products and a part of the noble metals. The second part of the reprocessing is performed by 'batch'. It aims to recover the fissile material and to separate the minor actinides from fission products. The reprocessing involves several chemical steps based on redox and acido-basic properties of the various elements contained in the fuel salt. One challenge is to perform a selective extraction of actinides and lanthanides in spent liquid fuel. Extraction of actinides and lanthanides are successively performed by a reductive extraction in liquid bismuth pool containing metallic lithium as a reductive reagent. The objective of this paper is to give a description of the several steps of the reprocessing retained for the molten salt fast reactor (MSFR) concept and to present the initial results obtained for the reductive extraction experiments realized in static conditions by contacting $\mathrm{LiF}-\mathrm{ThF}_{4}-\mathrm{UF}_{4}-\mathrm{NdF}_{3}$ with a lab-made Bi-Li pool and for which extraction efficiencies of $0.7 \%$ for neodymium and $14.0 \%$ for uranium were measured. It was concluded that in static conditions, the extraction is governed by a kinetic limitation and not by the thermodynamic equilibrium.
\end{abstract}

Key words: molten salt reactor $\bullet$ reductive extraction $\bullet$ fluoride molten salt $\bullet$ pyrochemistry

D. Rodrigues, G. Durán-Klie, S. Delpech ${ }^{凶}$

Institut de Physique Nucléaire, CNRS-IN2P3,

Univ. Paris-Sud, Université Paris-Saclay,

91406 Orsay Cedex, France,

E-mail: delpech@ipno.in2p3.fr

Received: 19 June 2015

Accepted: 16 September 2015

\section{Introduction}

The nuclear fuel processing is a requisite for nuclear energy to be a clean and sustainable energy. Nuclear reprocessing technology was developed to chemically separate and recover fissionable material from irradiated nuclear fuel. Then, the aim of reprocessing is to free the unspent nuclear fuel from the radioactive fission products and to separate the fertile and fissile materials, ${ }^{238} \mathrm{U}$ and ${ }^{239} \mathrm{Pu}$ or ${ }^{232} \mathrm{Th}$ and ${ }^{233} \mathrm{U}$, depending on the fuel cycle considered. In a closed fuel cycle (advocated for GEN IV reactor systems) fertile and fissile matters are put back in the fuel cycle while fission products are treated and disposed in deep storage. When the fuel is liquid as it is the case for the molten salt reactor (MSR) concept, the pyro-reprocessing is obvious. Pyrochemical reprocessing [1] has been under way in the world since many years and in the USA since the late 1950s [2]. Various techniques were studied [3]: alloy melting, fission product volatilization and adsorption, fluoride and chloride volatility methods, redox solvent, extraction between liquid salts and metal phases, precipitation and fractional crystallization, electrowinning and electro-refining of actinide metals and oxides. In recent years, a global reprocessing scheme has been established in the frame of the EURATOM EVOL program and these processes are 
currently being studied experimentally in the frame of national and European research programmes. The several elementary steps involving in the scheme, have been demonstrated from a thermodynamic point of view. The first part of this paper presents the pyro-reprocessing scheme of the molten salt fast reactor (MSFR) which is the concept of MSR derived from MSRE and MSBR concepts (ORNL concepts) $[4,5]$ and developed by CNRS [6] in the frame of the EVOL project, the description of each step and the behavior of the several elements during the treatment.

In the second part of the paper, reductive extraction experiments will be presented especially the removal of uranium (to simulate actinides product) and neodymium (to simulate lanthanides product) from the spent liquid fuel to the Bi-Li pool.

\section{Description of MSFR reprocessing}

\section{General description and objectives}

The MSFR concept is an innovative concept of MSR developed by CNRS since 2004. Contrary to the numerous previous MSR concepts [7], MSFR is operated in a fast neutron spectrum due to the removal of (i) graphite in the core and (ii) $\mathrm{BeF}_{2}$ in the molten salt composition. The salt is constituted of LiF-ThF $4^{-}\left(\mathrm{UF}_{4} / \mathrm{UF}_{3}\right)$ (77-19-4 mol\%). The working temperature is ranging between 650 and $850^{\circ} \mathrm{C}$.

The objectives of the reprocessing are:

- The production of ${ }^{233} \mathrm{U}$, necessary to insure nuclear energy sustainability: MSFR is a breeder concept. ${ }^{233} \mathrm{U}$ produced during reactor operation has to be removed to feed new reactors. Then, a reprocessing of the salt is required.

- The extraction of fission products (FPs): fission products have to be removed mainly because of their low solubility which can induce the formation of solid particles in the reactor. The neutron captures of lanthanides which were a drawback in the previous concepts (operated in thermal neutron spectrum) is not an issue in fast neutron spectrum, their capture cross section being very low in the energy range of the fast neutron spectrum.

- The back introduction of actinides (An) in the reactor core: aiming to close the fuel cycle, MSFR is also a burner concept. The separation FPs/An leads to decrease strongly the wastes toxicity because minor actinides (MA) are the most serious contributors to the toxicity and duration of the life of ultimate waste.

The reprocessing scheme proposed for MSFR is given Fig. 1. It was established considering the chemistry of the elements in the fuel salt. Each step is based on redox and acido-basic properties of the various elements.

Figure 1 shows that the reprocessing is divided in two parts: the on-line reprocessing which consists in the injection of helium gas in the core and the off-line reprocessing which is realized by batch and constituted of several steps. The volume of salt

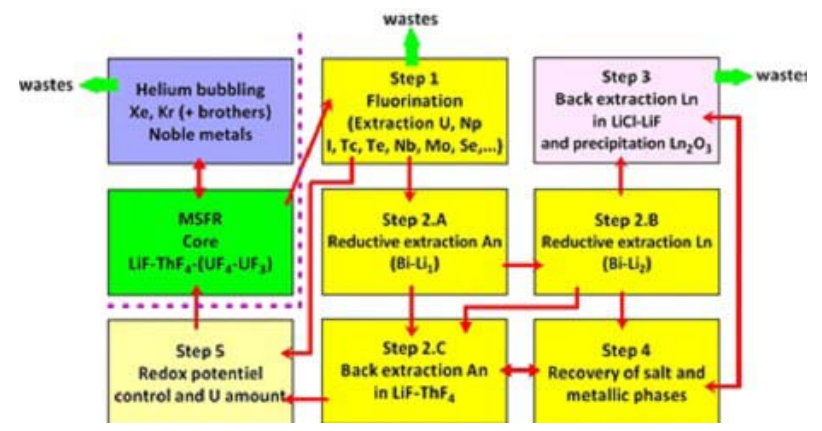

Fig. 1. Reprocessing scheme of MSFR concept.

removed from the core to be treated by day is about 40 liters.

Unlike the concept MSBR developed by the Oak Ridge National Laboratory (ORNL) in the 1960s [4, 5], the special reprocessing of ${ }^{233} \mathrm{~Pa}$ is not an issue in the MSFR concept (i) because it operates in a fast neutron spectrum and (ii) because a fertile blanket (constituted of the fused salt $\mathrm{LiF}^{2} \mathrm{ThF}_{4}(77-23 \mathrm{~mol} \%$ ) dedicated to ${ }^{233} \mathrm{U}$ production) is included in the concept [7]. In the MSBR concept, due to the neutron captures occurring on ${ }^{23} \mathrm{~Pa}$ and FPs, the optimized rate of reprocessing was about $4000 \mathrm{~L} /$ day. In the MSFR concept, the reprocessing rate is strongly decreased to $40 \mathrm{~L} /$ day and no dedicated step for ${ }^{233} \mathrm{~Pa}$ removal is required in the scheme.

\section{The reprocessing step by step}

\section{On-line reprocessing}

Helium is a gas with a very low solubility in molten fluoride salts. This property leads to use helium injection in the core (i) to help the removal of the gaseous fission products, particularly xenon and krypton which are neutron poisons and (ii) to allow the extraction of the noble metals produced in their metallic state by a physical process similar to flotation.

\section{Off-line reprocessing}

The spent fuel salt treated in this part of the reprocessing is the salt removed by batch from the core, thus $40 \mathrm{~L} /$ day.

Step 1: Fluorination

This step consists in the injection of fluorine gas in the used fuel salt. Fluorine gas production is carried out by an electrolytic reaction:

$$
2 \mathrm{HF} \rightarrow \mathrm{H}_{2(\mathrm{~g})}+\mathrm{F}_{2(\mathrm{~g})}
$$

In this way, all the elements are oxidized to their higher oxidation step by the chemical reaction:

$$
\mathrm{MF}_{\mathrm{X}}+\mathrm{F}_{2(\mathrm{~g})} \rightarrow \mathrm{MF}_{(\mathrm{X}+2)}
$$

In some cases, the species $\mathrm{MF}_{(\mathrm{X}+2)}$ are in their gaseous state and naturally removed from the salt. That is case of uranium, neptunium and numerous fission products $(\mathrm{Cl}, \mathrm{Br}, \mathrm{O}, \mathrm{S}, \mathrm{Ga}, \mathrm{I}, \mathrm{Sn}, \mathrm{Sb}, \mathrm{Pb}, \mathrm{Bi}$, $\mathrm{Tc}, \mathrm{Te}, \mathrm{Se}, \mathrm{Ti}, \ldots)$. The facility to perform the fluorina- 
tion step was described by the ORNL [8]. To avoid the corrosion of the structural material, the wall of the reactor is cooled by a NaK coolant. That leads to the formation inside the reactor of a frozen wall of salt which protects the materials against corrosion.

After separation from the salt, the gaseous elements are absorbed by NaF traps. By heating $\mathrm{NaF}$ traps at given temperatures, the actinides (U, Np) are separated from the FPs. Then, the elements are reduced by a chemical reaction with $\mathrm{H}_{2}$ :

$$
\mathrm{MF}_{(\mathrm{X}+2)}+\mathrm{H}_{2(\mathrm{~g})} \rightarrow \mathrm{MF}_{\mathrm{X}}+2 \mathrm{HF}_{(\mathrm{g})}
$$

The actinides are back introduced in the core and the fission products are sent to waste storage.

Step 2: Reductive extractions (2.A and 2.B)

The steps 2.A and 2.B are dedicated to the extraction of respectively non-gaseous actinides and lanthanides. These two steps are performed by the same method, the reductive extraction which consists by contacting the fuel salt with a liquid metal. The liquid metal is constituted of a mixture of bismuth and lithium. $\mathrm{Bi}$ is the solvent metal and $\mathrm{Li}$ the reductive element which allows the transfer of the elements dissolved in the salt to the liquid metal by a chemical reduction. The chemical reaction is given by:

$$
\begin{gathered}
z \mathrm{Li}_{\mathrm{LM}}+\left(\mathrm{AnF}_{z} \text { or } \mathrm{LnF}_{z}\right)_{\mathrm{MS}} \rightarrow(\text { An or } \mathrm{Ln})_{\mathrm{LM}} \\
+z \mathrm{LiF}_{\mathrm{MS}}
\end{gathered}
$$

The efficiency of the extraction of An and Ln and the selectivity of the separation An/Ln depend on the composition of the two metallic phases involving in the steps 2.A and 2.B. These compositions have been optimized using an extraction model established recently [9] by combining bibliographic and thermodynamic data. The solvation effect in the molten salt was assessed based on the analysis of experimental data obtained by Ferris et al. [10,11] and Moriyama et al. [12-14]. The experimental database established by Lebedev [15] was used for the solvation properties of the elements in the metallic phase. This analysis leads to establish the following relationships for the extraction efficiency of the element M [9]:

$$
\begin{aligned}
\mu(\mathrm{M} / \mathrm{Li}) & =\frac{1}{1+10^{\lambda(\mathrm{M} / \mathrm{Li})}} \text { with } \\
\lambda(\mathrm{M} / \mathrm{Li}) & =\frac{z}{m}\left(\mathrm{E}_{\mathrm{Li}}^{\circ}-\mathrm{E}_{\mathrm{M}}^{\circ}\right)-\log \Gamma_{\mathrm{M} / \mathrm{Li}}+\log \frac{\gamma(\mathrm{M})}{\gamma(\mathrm{Li})^{z}} \\
& +z \log \frac{x(\mathrm{LiF})}{x(\mathrm{Li})}+\log \frac{n(\mathrm{MS})}{n(\mathrm{LM})}
\end{aligned}
$$

In these relationships, $\mu(\mathrm{M})$ denotes the extraction efficiency of $\mathrm{M}, n(\mathrm{MS})$ and $n(\mathrm{LM})$ are respectively the numbers of moles of molten salt and of liquid metal, $\gamma(i)$ is the activity coefficient of $i$ (in liquid metal or molten salt), $x(i)$ - the mole fraction of $i$ in liquid metal or in molten salt, $\mathrm{E}_{i}$ - the standard potential of $i, z-$ the valence of the element $\mathrm{M}$, $m=2.3 \mathrm{RT} / \mathrm{F}$, with R - the ideal gas constant, $\mathrm{T}-$ the temperature and $\mathrm{F}$ - the Faraday constant.

The term $\Gamma_{\mathrm{M} / \mathrm{Li}}$ represents solvation in the molten salt. The expression for $\Gamma_{\mathrm{M} / \mathrm{Li}}$ in the case of $\mathrm{Li}$ as the reducing element is:

$$
\log \Gamma_{\mathrm{M} / \mathrm{Li}}=\frac{\log \left(\gamma\left(\mathrm{MF}_{z}\right)\right)}{\gamma(\mathrm{LiF})^{2}}
$$

Using these relationships it is possible to calculate the theoretical efficiency of lanthanides and actinides as a function of the composition of the Bi-Li pool by varying $x(\mathrm{Li})$. This approach was retained to propose the composition of the solvent metal for the two extraction steps: to perform actinides extraction without lanthanides extraction (step 2.A), Bi-Li (0.1 mol\%) and for the lanthanides extraction (Step 2.B), Bi-Li (10 mol\%). In these conditions, the number of stages required to reach $99 \%$ of efficiency can be calculated for each element. When the solvent metal Bi-Li contains $0.1 \mathrm{~mol} \%$ of $\mathrm{Li}$, only actinides are extracted [9]. Protactinium is stable under oxidation state (IV) in fluoride salts. It is also reduced by reductive extraction [10]. Thorium will be reduced in Bi-Li pool as shown in several papers [10-14] but its concentration will be limited by its solubility which is very low (less than $1 \mathrm{~mol} \%$ ) and depends on the amount of $\mathrm{Li}$ in $\mathrm{Bi}$ [16].

Step 2.C: Back extraction of actinides

After the steps 2.A and 2.B, the salt is clean and constituted of LiF-ThF 4 . By contacting the metallic phase which contains the actinides (after step 2.A) and the clean salt, actinides are transferred from the metal to the salt by an anodic oxidation. The counter electrode is a fresh Bi pool.

Step 3: Back extraction of lanthanides

The back extraction of lanthanides is realized by anodic oxidation of the Bi pool which contains the lanthanides transferred during the step 2.B. The counter electrode proposed is a fresh $\mathrm{Bi}$ pool in which Li will be electrochemically reduced. The back extraction is realized in a molten salt constituted of the eutectic mixture $\mathrm{LiCl}-\mathrm{LiF}(70-30 \mathrm{~mol} \%)$ whose melting point is $500^{\circ} \mathrm{C}$. After oxidation of lanthanides and dissolution in the molten salt, the lanthanides are precipitated under oxides. Introduction in the molten salt of $\left(\mathrm{Ar}-\mathrm{H}_{2} \mathrm{O}\right)$ gas is performed in order to precipitate solid $\mathrm{Ln}_{2} \mathrm{O}_{3}$. The chemical reaction is given by:

$$
\begin{aligned}
2\left(\mathrm{LnF}_{3} \text { or } \mathrm{LnCl}_{3}\right)+3 \mathrm{H}_{2} \mathrm{O}_{(\mathrm{g})} & \rightarrow \mathrm{Ln}_{2} \mathrm{O}_{3} \\
+ & 6(\mathrm{HF} \text { or } \mathrm{HCl})_{(\mathrm{g})}
\end{aligned}
$$

The products of this reaction are solid compounds $\left(\mathrm{Ln}_{2} \mathrm{O}_{3}\right)$ which are separated from the salt. $\mathrm{HCl}$ or $\mathrm{HF}$ are under gaseous state and easily removed from the salt. Therefore, the composition of the salt is not modified by this reaction. The precipitation of lanthanide oxides has been demonstrated and a patent related to this method has been filled [17]. The lanthanides under oxide form are sent to waste storage.

Step 4: Recovery of salt and metallic phases

During the steps 2.A, 2.B, 2.C and 3 the composition of the several phases, both salts and metals have been modified. Indeed the extraction of An and $\mathrm{Ln}$ is accompanied by an increase of $\mathrm{LiF}$ amount in the fuel salt $\left(\mathrm{LiF}_{\mathrm{ThF}}\right)$ and a decrease of metallic $\mathrm{Li}$ in the Bi solvent. Therefore the recovery of the composition of all the phases is required to have a balance of the reprocessing equal to zero. Electrochemical techniques are envisaged to perform this 


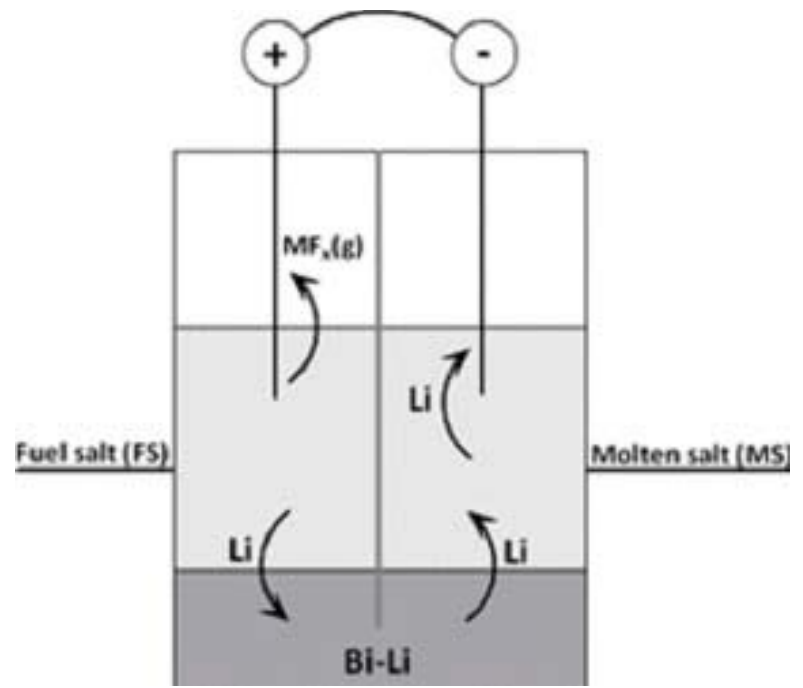

Fig. 2. Electrochemical device proposed to remove the excess of LiF due to Ln extraction in the fuel salt.

step and particularly a double electrochemical cell with a buffer metallic phase as shown in Fig. 2 . This cell insures the reduction of the excess of $\mathrm{LiF}$ contained in the molten salt $\mathrm{LiF}^{-\mathrm{ThF}_{4}}$ without any modification of the other phases.

Step 5: Introduction of ${ }^{23} \mathrm{U}$ and redox control of the fuel salt

The salt contains $\mathrm{LiF}^{-T h F} \mathrm{~T}_{4}$ and all the actinides introduced by the step 2.C. During step 5, the actinides removed during the fluorination step are introduced in the fuel salt after reduction in presence of hydrogen gas (Eq. (3)). The amount of ${ }^{23} \mathrm{U}$ introduced in this step is optimized for the proper operation of the reactor. Introduction of uranium also permits the control of the redox potential of the fuel salt. The redox potential of the salt is a main parameter to avoid the chemical corrosion of the structural material [18]. In order to decrease the redox potential, addition of metallic uranium is proposed.

\section{The behavior of the elements in the reprocessing}

The behavior of the elements at each step of the reprocessing depends on their redox and acido-basic properties in the fuel salt LiF-ThF 4 . The knowledge of thermodynamic and solvation data is required to predict the behavior of the elements during each step. Currently only a few activity coefficients have been assessed [9] in $\mathrm{LiF}^{-} \mathrm{ThF}_{4}$ molten salt based on experimental results [10-14]. More data are available concerning the activity coefficients of elements in $\mathrm{Bi}$ solvent [15]. But for most components, only estimated behavior based on thermodynamic data and without taking account of solvation effects can be done.

\section{Experimental measurements of the reductive extraction step}

Reductive extraction experimental tests have been carried out to validate the feasibility of this step to remove lanthanides from $\mathrm{LiF}_{\mathrm{ThF}} \mathrm{Tholten}_{4}$ salt even if their redox potentials are lower than the electroactivity limit of the salt.

\section{Technical}

The storage and handling of all chemicals are carried out in a glove box with purified argon atmosphere because fluoride and chloride compounds have a tendency to absorb water molecules. Thorium fluoride powder is provided by Solvay Company and the other chemicals are provided by Sigma-Aldrich. Their purity is higher than $99.9 \%$. LiF and $\mathrm{ThF}_{4}$ are mixed and dried under argon before melting. $\mathrm{LiCl}$ and $\mathrm{LiF}$ mixture (used for the preparation of $\mathrm{Bi}-\mathrm{Li}$ metallic solvent) is prepared in the same manner. The melting procedure has been described previously [19]. The tubular furnace $(80 \mathrm{~cm}$ diameter $)$ used is connected to a regulation monitor provided by Eraly/France. Thermodynamic calculations of redox potentials are performed using a database and software HSC Chemistry for Windows created by Outokumpu in Finland. Elementary analysis of bismuth and salt phases was performed by inductively coupled plasma atomic emission spectroscopy (ICP-AES) analysis (Agilent 720-ES). Potentiometric and voltammetric measurements are performed with EG\&G potentiostat-galvanostat mod. 263 coupled with a PC computer.

The electrochemical cell used to prepare $\mathrm{Bi}-\mathrm{Li}$ solvent (Fig. 3) is described as follows:

The tungsten working electrode is prepared using a tungsten wire ( $1 \mathrm{~mm}$ diameter, Goodfellow). The bismuth pool working electrode is prepared using a tungsten wire dipped into a Pyrex basket containing liquid bismuth. The tungsten wire is just useful to create an electrical contact between the liquid bismuth and the potentiostat-galvanostat. The reference electrode is constituted of a silver wire $(1 \mathrm{~mm}$ diameter, Goodfellow) dipped into a $\mathrm{LiCl}-\mathrm{KCl}-\mathrm{AgCl}$

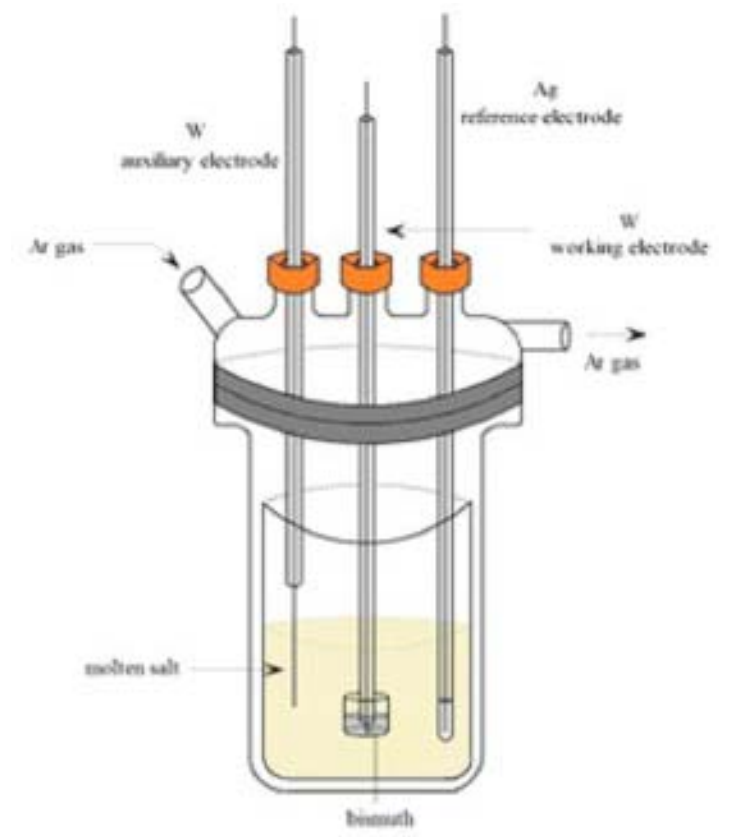

Fig. 3. Electrochemical cell used to prepare the bismuth-lithium liquid phase in $\mathrm{LiF}-\mathrm{LiCl}$ at $525^{\circ} \mathrm{C}$. 
$\left(0.75 \mathrm{~mol} \cdot \mathrm{kg}^{-1}\right)$ mixture, contained in a Pyrex glass tube. The auxiliary electrode is made of a tungsten wire. The Bi-Li alloys prepared are stored in an inert glove box before their use for reductive extraction.

Experiments of reductive extraction are realized in a glassy carbon crucible which contains both molten salt and the metallic phase. The device is introduced in a closed quartz cell and the experiments are carried out under argon atmosphere at $600^{\circ} \mathrm{C}$. The number of moles of molten salt and metallic solvent introduced are respectively noted $n(\mathrm{MS})$ and $n(\mathrm{LM})$.

Samples of Bi-Li and salt are regularly collected for analysis by manual vacuum aspiration of small amounts of liquid Bi-Li in situ. The analyses are realized by ICP-AES after dissolution of the alloys and the salts in acidic solutions. We observe troubles with the analysis of the fluoride salts. In all cases, the concentration determined by ICP-AES is lower than the expected values. Tests have been done with given amounts of salts dissolved in acidic solutions and the analysis gave incorrect results. That can be due to a partial dissolution or to adsorption of fluoride on the containers. Currently, the protocol of analysis of fluoride salt is under studied. It is the reason why this paper will present only the analysis of the metallic phase.

\section{Results and discussion}

\section{Bi-Li metallic solvent preparation}

The preparation of the bismuth-lithium liquid phase is done by electrolysis of $\mathrm{LiCl}-\mathrm{LiF}$ (70-30 $\mathrm{mol} \%)$ molten salt on liquid bismuth pool electrode at a working temperature of $525^{\circ} \mathrm{C}$. The choice of the salt is fundamental; $\mathrm{LiCl}-\mathrm{LiF}$ is selected because lithium cation is the only one able to be reduced during the electrolysis. Previous studies realized using $\mathrm{LiCl}-\mathrm{KCl}$

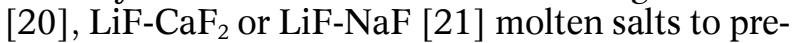
pare Bi-Li solvents have evidenced the reduction in the bismuth pool of Li but also of $\mathrm{K}, \mathrm{Ca}$ and $\mathrm{Na}$ with various concentrations. The only way to produce pure Bi-Li solvent with a given composition is to use LiCl-LiF molten salt. Voltammograms are recorded in this media on a solid tungsten electrode and on a liquid bismuth electrode (Fig. 4). The electroactivity range is $3.71 \mathrm{~V}$ on a tungsten electrode and $1.46 \mathrm{~V}$ on a bismuth electrode. On the cathodic side, the reduction of $\mathrm{Li}(\mathrm{I})$ to $\mathrm{Li}$ metal occurs at $-2.59 \mathrm{~V}$ vs. $\mathrm{AgCl} / \mathrm{Ag}$ on the tungsten electrode (peaks $\mathrm{II}_{\mathrm{A}}-\mathrm{II}_{\mathrm{C}}$ ) and at $-1.75 \mathrm{~V}$ vs. $\mathrm{AgCl} / \mathrm{Ag}$ on the bismuth electrode (peaks $\mathrm{II}_{\mathrm{A}}-\mathrm{II}_{\mathrm{C}}$ ). On the anodic side, the oxidation of $\mathrm{Cl}^{-}$to chlorine gas occurs at $+1.12 \mathrm{~V}$ vs. $\mathrm{AgCl} / \mathrm{Ag}$ on tungsten electrode $\left(\mathrm{I}_{\mathrm{A}}\right)$. On bismuth electrode, the anodic limit corresponds to the oxidation of $\mathrm{Bi}$ to $\mathrm{Bi}(\mathrm{III})$ and it occurs at $-0.10 \mathrm{~V}$ vs. $\mathrm{AgCl} / \mathrm{Ag}\left(\mathrm{I}_{\mathrm{A}}{ }_{\mathrm{A}}\right)$.

The reduction of $\mathrm{Li}(\mathrm{I})$ to $\mathrm{Li}$ in liquid bismuth is performed by electrolysis at applied current of -0.5 A during 8 hours. The process is followed by recording the charge and the potential of bismuth pool as function of time (Fig. 5). At the end of electrolysis ICP-AES analysis of a $\mathrm{Bi}-\mathrm{Li}$ pool sample confirms the composition of the metallic solvent.

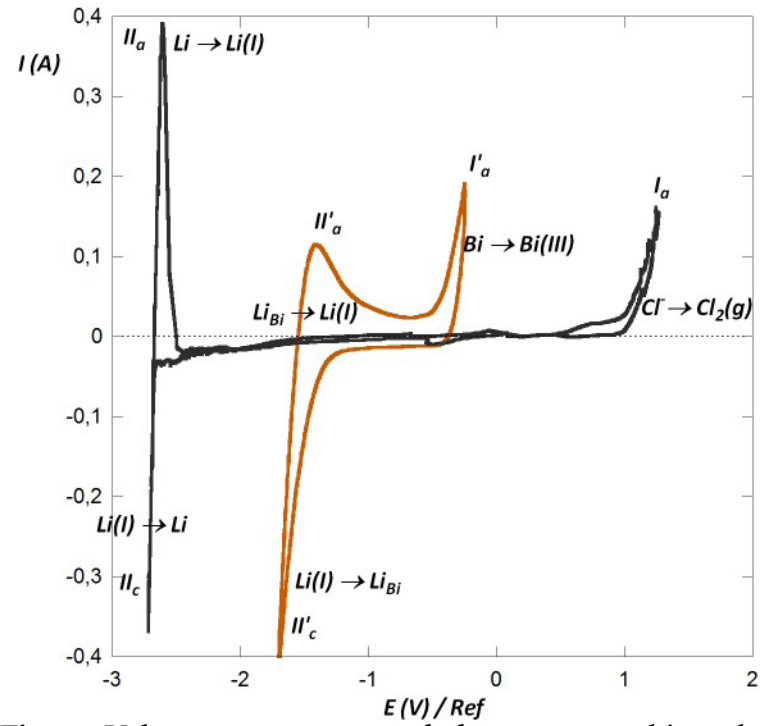

Fig. 4. Voltammograms recorded on two working electrodes, bismuth (orange) and tungsten (black) at $525^{\circ} \mathrm{C}$ in $\mathrm{LiCl}-\mathrm{LiF}$ at $0.1 \mathrm{~V} / \mathrm{s}$.

Electrolysis was done various times and the Faraday efficiency is around $95 \%$.

\section{Reduction extraction experiments}

The study of the reductive extraction was carried out in $\mathrm{LiF}^{-\mathrm{ThF}_{4}}(77-23 \mathrm{~mol} \%)$ salt at $600^{\circ} \mathrm{C}$. An addition of $0.05 \mathrm{~mol} \%$ of neodymium simulates the lanthanides in the spent fuel. Based on the same logic, an addition of $0.05 \mathrm{~mol} \%$ of uranium simulates the actinides. The objective of this first experiment is not to test the selectivity of the extraction but to remove both $\mathrm{U}$ and $\mathrm{Nd}$ and to give an assessment of the extraction efficiency (noted $\mu$ ) and to validate the method. In experimental conditions chosen, the extraction efficiency calculated using the model (based on thermodynamic and solvation data available in the literature) and the relation established in [9] is higher than $95 \%$ for $\mathrm{U}$ and $\mathrm{Nd}$.

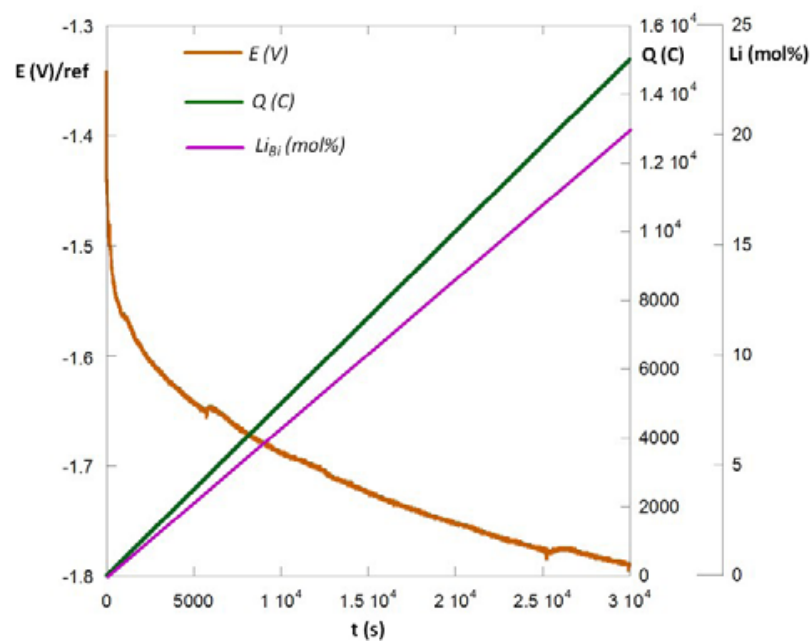

Fig. 5. Evolution of the potential (orange) of the bismuth and of the charge (green) and of the amount of Li introduced in $\mathrm{Bi}$ (pink) as a function of time during electrolysis at an applied current of $-0.5 \mathrm{~A}$. 
Firstly, reductive extraction of uranium and neodymium was tested. The molten salt $\mathrm{LiF}^{-T_{h} \mathrm{~F}_{4}}{ }^{-}$ $-\mathrm{UF}_{4}-\mathrm{NdF}_{3}\left(0.05 \mathrm{~mol} \%\right.$ of $\mathrm{UF}_{3}$ and $\left.\mathrm{NdF}_{3}\right)$ was prepared and introduced in a reactor containing Bi-Li ( $\approx 10 \mathrm{~mol} \%$ ) prepared following the protocol previously described. The mole ratio of the two liquid phases $(n(\mathrm{MS}) / n(\mathrm{LM}))$ is equal to 2.6 . Based on the samples ICP-AES analysis, extraction efficiency is calculated for uranium and neodymium as a function of time (Fig. 6). All the experiments are reported in this figure. We observe an increase of the extraction efficiency with time and stabilization after about $90 \mathrm{mn}$. The extraction efficiency measured is close to $14 \%$ for uranium and $0.6 \%$ for neodymium. The efficiency values obtained are lower than the calculated ones. That can be due to a thermodynamic or kinetic limitation. Another experiment was done with a mole ratio (molten salt over metallic phase: $n(\mathrm{MS}) / n(\mathrm{ML})$ ) equal to 5 . Indeed, in these conditions, if the limitation is due to the thermodynamic equilibrium, the extraction efficiency has to be significantly lower. Using the relation previously established to calculate the extraction efficiency only based on thermodynamic and solvation parameters [9], when the ratio $n$ (MS) $/ n$ (LM) varies from 2.6 to 5 , the extraction efficiency is reduced by 2 .

The next experiment was realized with a ratio of $n$ (MS) $/ n$ (LM) equal to 5 . The exchange surface between salt and metal remains constant. In this experiment, four stages of successive reductive extraction were realized. To perform four stages, each 90 min the metallic phase is totally removed from the reactor containing the molten salt and a new fresh Bi-Li phase (with the same composition and volume) is introduced in the crucible. The time of $90 \mathrm{~min}$ was chosen because it corresponds to a stabilization of the extraction. After these experiments, the samples of the four metallic phases are analyzed by ICP-AES to follow the extraction of $\mathrm{U}$ and $\mathrm{Nd}$ from the salt to the metallic solvent. The results obtained are presented as the variation of cumulative extraction efficiency $\mu^{*}$ (the total number of moles

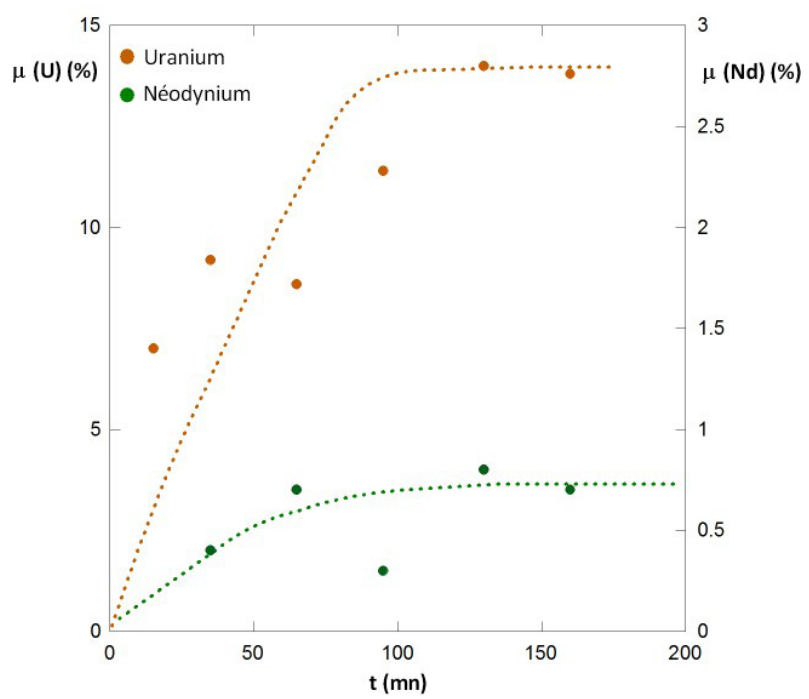

Fig. 6. Evolution of extraction efficiency of $\mathrm{U}$ and $\mathrm{Nd}$ with time $(n(\mathrm{MS}) / n(\mathrm{LM})=2.6)$.

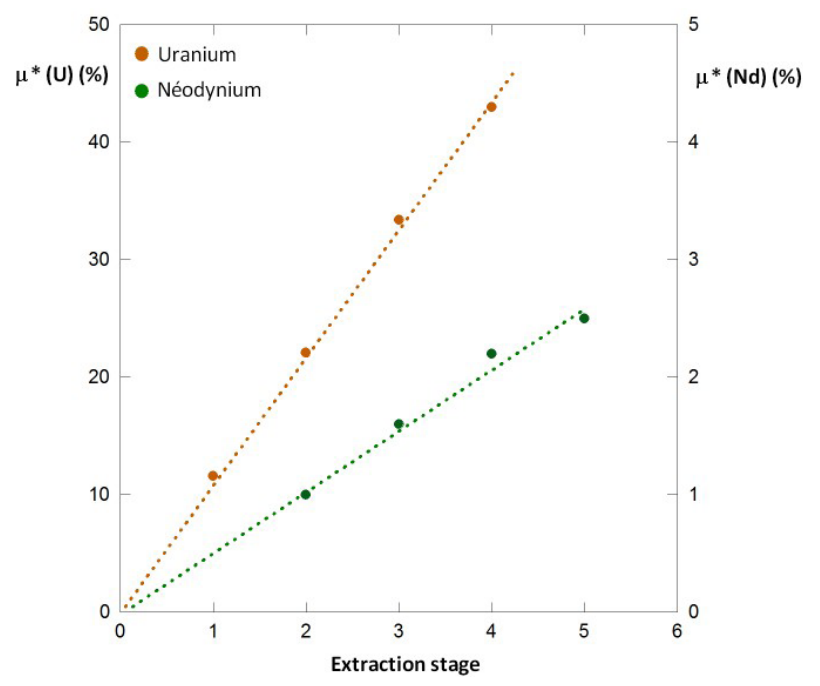

Fig. 7. Evolution of the global extraction efficiency $\mu^{*}$ for uranium and neodymium according to the time and number of stages $(n(\mathrm{MS}) / n(\mathrm{LM})=5)$.

extracted in the four metallic phases over the initial number of moles) with time (Fig. 7). An increase of $\mu^{*}$ is observed when the stage number increases both for uranium and neodymium. After four stages the global extraction efficiency $\mu^{*}$ values are $43 \%$ and $2.5 \%$ respectively for uranium and neodymium. The extraction efficiency measured for the first stage is close to that measured in the first experiment with the mole ratio of $(n(\mathrm{MS}) / n(\mathrm{LM}))$ equal to 2.6.

Thorium is also observed in the Bi-Li alloy after each extraction process (Fig. 8). The time of stabilization of the amount of $\mathrm{Th}$ in $\mathrm{Bi}$ is slightly higher than for Nd and U, close to $130 \mathrm{~min}$. Its concentration remains lower than its solubility determined by Smith [16] and the amount in Bi-Li alloy is no dependent on the ratio $n(\mathrm{MS}) / n(\mathrm{LM})$. That confirms the involvement of $\mathrm{Th}$ in the kinetic of extraction.

Then, the extraction is governed not by thermodynamic but by a kinetic step which decreases the efficiency of extraction. This kinetic step could be explained by a low diffusional process of the reduced species from the interface to the bulk of the metallic phase. The kinetic limitation can be related to the formation of solid bismuthides of $\mathrm{Nd}$, $\mathrm{U}$ or Th at the salt-bismuth interface. The extraction rate can be limited by solubility of these compounds and by the mass transfer process in the Bi pool as proposed by Moriyama et al. [22]. The improvement of extraction efficiency will require improvement of technical apparatus to perform the extraction in dynamic conditions. Indeed, Lemort et al. [23] have studied the influence of different types of stirring, classical agitation and inductive current. They observed a strong influence of the stirring on the extraction kinetic, the extraction being limited by the formation of a solid layer at the interface Bi-salt.

\section{Conclusions}

The thermodynamic study shows a lack of thermodynamic and/or solvation data to predict which 


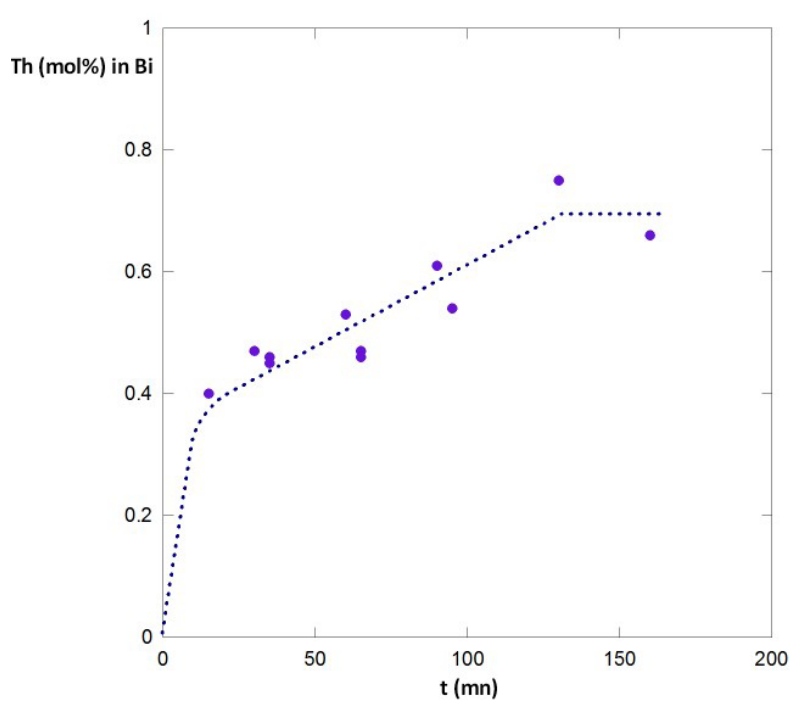

Fig. 8. Evolution of extraction efficiency of Th with time in various conditions $(n(\mathrm{MS}) / n(\mathrm{LM})=2.6$ to 5$)$.

reprocessing step will be able to extract all fission products. More particularly the activity coefficient of elements in the fuel salt and the activity coefficient of elements inside the bismuth liquid phase are missing for a most part of fission products.

The reductive extraction has to be studied in particular as it is involved twice in the process, and because the success of the MSFR reprocessing is closely linked to the success of these steps.

Firstly, the production of bismuth-lithium liquid phase is now well controlled by the electrolysis process performed in $\mathrm{LiCl}-\mathrm{LiF}$ molten salt, the only media able to provide a pure and clean bismuth-lithium metallic phase.

The study of the reductive extraction was performed with uranium and neodymium inside LiF$-\mathrm{ThF}_{4}$ molten salt at $600^{\circ} \mathrm{C}$. The analysis shows low extraction efficiency either for $\mathrm{U}$ and $\mathrm{Nd}$. Varying the experimental conditions do not modify the extraction efficiency and we clearly demonstrated that the extraction is controlled by the kinetic of the transfer and not by the thermodynamic equilibrium. Subsequently, improving the reductive extraction requires not only the knowledge of the solvation and thermodynamic data but also of the mass transfer kinetic of elements from the molten salt to the metallic solvent. More studies will be performed to determine the activity coefficients and calculate thermodynamically the best condition to perform the reductive extraction. In parallel, technical investigations have to be realized to improve the devices to perform reductive extraction in dynamic conditions in order to increase the mass transfer kinetic.

Acknowledgments. The research leading to these results has received funding from the European Community's Seventh Framework Programme under grant agreement no. 249696 EVOL, from the French program NEEDS-SN from Solvay Company for CIFRE grant, from CAMPUS-France and FOUNDAYACUCHO for grant.

\section{References}

1. OECD. (2004). Pyrochemical separations in nuclear applications. Status report of OECD.

2. Long, J. T. (1978). Engineering for nuclear fuel reprocessing. 2nd ed. (pp. 242-272). American Nuclear Society.

3. Laidler, J. J., Battles, J. E., Miller, W. E., Ackerman, J. P., \& Carls, E. L. (1997). Development of pyroprocessing technology. Prog. Nucl. Energy, 31(1/2), 131.

4. Bettis, E. S., \& Robertson, R. C. (1970). The design and performance features of a single-fluid molten salt breeder reactor. Nucl. Appl. Technol., 8, 190-207.

5. Whatley, M. E., McNeese, L. E., Carter, W. L., Ferris, L. M., \& Nicholson, E. L. (1970). Engineering development of the MSBR fuel recycle. Nucl. Appl. Tech., 8, 170-178.

6. Delpech, S., Merle-Lucotte, E., Heuer, D., Allibert, M., Ghetta, V., Le-Brun, C., Doligez, X., \& Picard, G. S. (2009). Reactor physic and reprocessing scheme for innovative molten salt reactor system. J. Fluor. Chem., 130(1), 11-17.

7. Delpech, S. (2013). Molten salts for nuclear applications. In F. Lantelme, \& H. Groult (Eds.), Molten salt chemistry: from lab to applications (pp. 497-520). USA: Elsevier.

8. Briggs, R. B. (1966). Molten salt reactor program semiannual progress report for period ending February 28, 1966. USA: Oak Ridge National Laboratory (Report no. 3936).

9. Delpech, S. (2013). Possible routes for pyrochemical separations: focus on the reductive extraction in fluoride media. Pure Appl. Chem., 85, 71-87.

10. Ferris, L. M., Mailen, J. C., Lawrance, J. J., Smith, F. J., \& Nogueira, E. D. (1970). Equilibrium distribution of actinide and lanthanide elements between molten fluoride salts and liquid bismuth solutions. J. Inorg. Nucl. Chem., 32, 2019-2035.

11. Ferris, L. M., Smith, F. J., Mailen, J. C., \& Bell, M. J. (1972). Distribution of lanthanide and actinide elements between molten lithium halide salts and liquid bismuth solutions. J. Inorg. Nucl. Chem., 34, 2921-2933.

12. Moriyama, H., Yajima, K., Nunogane, N., Ohmura, T., Moritani, K., \& Oishi, J. (1984). Reductive extraction of lanthanide and actinide elements from molten LiF$-\mathrm{BeF}_{2}$ salt into liquid bismuth. J. Nucl. Sci. Technol., 21(12), 949-958.

13. Moriyama, H., Yajima, K., Tominaga, Y., Moritani, K., \& Oishi, J. (1983). Mechanism of distribution of actinide elements between molten fluoride salts and liquid bismuth solutions. In Proceedings of the 1st International Symposium on Molten Salt Chemistry and Technolology, 20-22 April 1983 (pp. 419-422). Kyoto, Japan.

14. Moriyama, H., Seshimo, T., Moritani, K., Ito, Y., \& Mitsugashira, T. (1994). Reductive extraction behavior of actinide and lanthanide elements in molten salt and liquid metal binary phase systems. J. Alloys Compd., 213/214, 354-359.

15. Lebedev, V. A. (1993). Selectivity of liquid metal electrodes in molten halides. Cheyabinsk: Metallurgiya.

16. Smith, F. J. (1972). The solubilities of thorium and neodymium in liquid lithium-bismuth solutions. $J$. Less-Com. Met., 27, 195-200.

17. Laplace, A., Vigier, J. F., Plet, T., Renard, C., Abraham, F., Slim, C., Delpech, S., \& Picard, G. (2011). Elaboration de solutions solides d'oxydes d'actinides et de lanthanides en milieu sels fondus: application à un 
nouveau procédé de refabrication du combustible par voie pyrochimique. Patent no. FR 11/58572.

18. Delpech, S., Cabet, C., Slim, C., \& Picard, G. S. (2010). Molten fluorides for nuclear applications. Mat. Today, 13(12), 34-41.

19. Rouquette-Sanchez, S., \& Picard, G. S. (2004). Chalcogenide chemistry in molten salts. I. Selenium(IV) acido-basic and redox properties in the LiCl-KCl eutectic melt at $450,500,550$ and $600^{\circ} \mathrm{C}$. J. Electroanal. Chem., 572, 173-183.

20. Jaskierowicz, S. (2012). Extraction des actinides et des lanthanides du combustible du réacteur rapide à sels fondus. Thesis of Univ. Paris Sud.
21. Gibilaro, M., Bolmont, S., Massot, L., Latapie, L., \& Chamelot, P. (2014). On the use of liquid metals as cathode in molten fluorides. J. Electroanal. Chem., 726, 84-90.

22. Moriyama, H., Miyazaki, M., Asaoka, Y., Moritani, K., \& Oishi, J. (1991). Kinetics of reductive extraction of actinide and lanthanide elements from molten fluoride into liquid bismuth. J. Nucl. Mater., 182, 113-117.

23. Lemort, F., Boen, R., Allibert, M., Perrier, D., Fautrelle, Y., \& Etay, J. (2005). Kinetics of the actinides-lanthanides separation: mass transfer between molten fluorides and liquid metal at high temperatures. J. Nucl. Mater., 336, 163-172. 